\title{
Clinicopathological Profile of Anaemia Cases in Adults (20-60 years) Attending a Rural Hospital
}

\author{
Mangal Motilal Pandure* and Deepak Kumar Ghosh \\ Dept of Pathology, Pravara Institue of Medical Sciences. Deemed University.
}

\section{ABSTRACT}

Background: Anemia is a worldwide problem with highest incidence in developing countries. India has the highest prevalence of nutritional anemia predominantly in women and children.

Methods: An observational and analytical study was carried out for period of 12 months. We studied 261 adult patient for typing the anemia. We perform the hematology parameter by automated hematologyanalyzer,For confirmation PBS and bone marrow examination, serological test like serum iron profile, vit B12 and folic acid levels in blood is done

Result: Total 261 cases of anemia included in the study. Microcytic hypochromic anemia were $63.2 \%$ of cases, macrocytic anemia cases were $36.77 \%$ of cases. Large number of iron deficiency anemia's were seen in female with reproductive age group and megaloblastic anemia seen with age 50-60 years of age in both sex.

Conclusion: For the diagnosis of nutritional anemia haemogram by automated hematology parameter, PBS, serum iron profile , serum vit $\mathrm{B} 12$ and folic acid is required

Keywords: Iron Deficiency Anemia, Megaloblastic Anemia, Nonmegaloblastic Macrocytic Anemia, Nutritional Anemia.

\section{Introduction}

In 1992, World Health Organization(WHO) global estimates of anemia prevalence averaged $56 \%$, with range of $35-75 \%$ depending on geographic location. Prevalence of anemia seen in south Asia, among highest in world. In India recent data from national family health survey 1998/1999 stated that woman with reproductive age have higher prevalence rate concentration and impaired capacity to transport oxygen. ${ }^{[1]}$ It has multiple factor such as genetic- haemoglobinopathies, infectious- malaria, intestinal helminthes and nutritional- which includes iron deficiency as well as deficiency of vitamins such as folate vitamin A, B12 and minerals like cupper. ${ }^{[2]}$

The evaluation of cause of anemia includes complete blood count, peripheral smear, and reticulocyte count and serum iron indices. ${ }^{[3]}$ As per WHO classification, majority of subject $41.3 \%$ suffered from moderate anemia, while 18.4and 0.4 suffer from mild and severe anemia. In the study of NeelamDeshpande et al $70 \%$ of anemic subject had low MCV with high RDW suggestive of iron deficiency. ${ }^{[4]-}$

Uma Khandri and Archana Sharma stated that megaloblastic anemia was diagnosed from complete blood count, red cell indices, blood film examination and assay of two vitamins. Marrow examination was not essential for diagnosis. Cobalamine deficiency was responsible for megaloblastic anemia in majority of patient (65\%), combined (folate and cobalamine) seen in $12 \%$ and pure folate deficiency in $6 \%$ cases. $^{[5]}$

Hence the present study was carried out to find out commonest type of anemia in the rural population.

\section{Materials and Methods}

This is prospective study comprised of adult from outpatientand indoor department of a tertiary care in teaching hospital in Maharashtra, India. The period of study was from January 2015 to December 2015. Total261 patients with anemia's were selected for study with informed consent.

\section{Selection Criteria for cases}

Inclusion criteria(cases included in study)

- Male and female patient in the age group 20 to 60 years.

- $\quad$ Patient with HB value $10 \mathrm{gm} / \mathrm{dl}$ or less.

Exclusion criteria ; (cases excluded from study)

- Pregnant and lactating women due to physiological anemia

- Patient who were on treatment / therapy for any reason

Haemogram were performed by automated hematologyanalyzersysmex XN 1000. This instrument performed hematology analysis according to 
hydrodynamic focusing, flow cytometry method and SLS hemoglobin method.

Microcytic hypochromic anemia and macrocytic anemia were included in the study. Cases are classified in to microcytic and macrocytic anemia on the basis of MCV. Microcytic anemia is identified when MCV is $<80 \mathrm{fl}$, macrocytic anemia is identified when MCV exceeds 100fl, increased RDW in both and confirmed by Peripheral Blood Smear (PBS). PBS examinations were performed, we observed for anisopikilocytes, microcytes and macrocytes. ${ }^{[6]}$

Additional $5 \mathrm{ml}$ blood sample collected for special investigation for S. ferritin, $\mathrm{S}$ iron, TIBC, \% saturation for confirmation of microcytic anemia and $\mathrm{S}$ vit B12 and $\mathrm{S}$ folic acid estimation in macrocytic anemia.

Values done by automated hematologyanalyzer correlated withPBS findings, S. iron profile value, Vit B12 and folic acid levels. In cases of $\mathrm{Hb}$ deficiency syndrome cases with normal RDW and increased reticulocyte count, reticulocyte count was performed manually using supravital stain with methylene blue- showed dark blue granules in the cell identified as reticulocyte. Advised them to perform hemoglobin electrophoresis.

\section{Result}

Total number of cases in study: 261

Table 2 Distribution of cases according to age groups in microcytic hypochromic anemia:

Large number of iron deficiency anemia seen in female with age group of 20-29 years, followed by age group of 30-39 years, in reproductive age group there is no specific group affected in other type of anemia's.

Table3 Distribution of cases according to age group in macrocytic anemia

In nonmegaloblastic macrocytic anemia, cases with increased reticulocyte were ask to investigate for hemolyticanemia.

Table 4 Clinical features of microcytic hypochromic anemia:

Table 5 Clinical features -Macrocytic anemia:

Table 1: Age and sex distribution of anaemia in study;

\begin{tabular}{|c|c|c|c|}
\hline Serial number & Age group in years & Male & Female \\
\hline 1 & $20-29$ & $22(8.42 \%)$ & $73(27.96 \%)$ \\
\hline 2 & $30-39$ & $18(6.89 \%)$ & $40(15.32 \%)$ \\
\hline 3 & $40-49$ & $24(9.19 \%)$ & $18(6.89 \%)$ \\
\hline 4 & $50-60$ & $32(12.26 \%)$ & $34(13.02 \%)$ \\
\hline Total & & $\mathbf{9 6 ( 3 6 . 7 8 \% )}$ & $\mathbf{1 6 5 ( 6 3 . 2 1 \% )}$ \\
\hline
\end{tabular}

Table 2: Distribution of cases according to age groups in microcytic hypochromic anaemia:

\begin{tabular}{|c|c|c|c|c|c|c|c|c|}
\hline $\begin{array}{c}\text { Age group in } \\
\text { years }\end{array}$ & $\begin{array}{c}\text { Total number of cases with } \\
\text { microcytic hypochromic anaemia }\end{array}$ & \multicolumn{2}{|c|}{$\begin{array}{c}\text { Iron deficiency } \\
\text { anaemia }\end{array}$} & \multicolumn{2}{|c|}{$\begin{array}{c}\text { Anaemia of } \\
\text { chronic disease }\end{array}$} & \multicolumn{2}{c|}{$\begin{array}{c}\text { Haemoglobin } \\
\text { deficiency }\end{array}$} \\
\hline & Male & Female & Male & Female & Male & Female & Male & Female \\
\hline $20-29$ & 11 & 65 & 04 & 54 & 05 & 7 & 02 & 4 \\
\hline $30-39$ & 10 & 32 & 03 & 26 & 04 & 4 & 03 & 2 \\
\hline $40-49$ & 05 & 11 & 02 & 04 & 03 & 4 & 00 & 3 \\
\hline $50-60$ & 10 & 21 & 02 & 10 & 05 & 7 & 03 & 4 \\
\hline Total & 36 & 129 & 11 & 94 & 17 & 22 & 08 & 13 \\
& $(13.79 \%)$ & $(49.42 \%)$ & $(4.21 \%)$ & $(36.01 \%)$ & $(6.51 \%)$ & $(8.42 \%)$ & $(3.06 \%)$ & $(4.98 \%)$ \\
\hline
\end{tabular}

Table3: Distribution of cases according to age group in macrocytic anaemia :

\begin{tabular}{|c|c|c|c|c|c|c|}
$\begin{array}{c}\text { Age group in } \\
\text { years }\end{array}$ & \multicolumn{2}{|c|}{$\begin{array}{c}\text { Total number macrocytic } \\
\text { anaemia }\end{array}$} & \multicolumn{2}{c|}{ Megaloblasticanaemia } & \multicolumn{2}{c|}{$\begin{array}{c}\text { Nonmegaloblastic macrocytic } \\
\text { anaemia }\end{array}$} \\
\hline & Male & Female & Male & Female & Male & Female \\
\hline $20-29$ & 11 & 08 & 07 & 06 & 04 & 02 \\
\hline $30-39$ & 08 & 08 & 04 & 07 & 04 & 01 \\
\hline $40-49$ & 19 & 07 & 14 & 07 & 05 & 00 \\
\hline $50-60$ & 22 & 13 & 17 & 10 & 05 & 03 \\
\hline & 60 & 36 & 42 & 30 & 18 & 06 \\
& $(23.98 \%)$ & $(13.78 \%)$ & $(16.09 \%)$ & $(11.49 \%)$ & $(6.89 \%)$ & $(2.29 \%)$ \\
\hline
\end{tabular}


Table 4: Clinical features of microcytic hypochromic anaemia

\begin{tabular}{|c|c|c|c|c|}
\hline Sr no & Symptoms & Number of cases & Signs & Number of cases \\
\hline 1 & Fatigue, palpitation, weakness & 68 & Pale conjunctiva, pale tongue and pallar & 83 \\
\hline 2 & Menstrual bleeding & 38 & Angular stomatitis & 12 \\
\hline 3 & Urinary tract infection & 12 & Lower respiratory tract infection & 23 \\
\hline 4 & $\begin{array}{c}\text { Gastrointestinal bleeding, fresh } \\
\text { blood in stool }\end{array}$ & 15 & Haemorrhoids, Gl malignancy, maleana & 10 \\
\hline 5 & Chronic respiratory infection & 11 & Growth endometrium/cervix & 19 \\
\hline 6 & Post-menopausal bleeding & 14 & Rheumatoid arthritis & 08 \\
\hline 7 & Joint pain & 12 & DUB & 32 \\
\hline 8 & Dyspnea on exertion & 28 & &
\end{tabular}

Table 5: Clinical History-Macrocytic anaemia.

\begin{tabular}{|c|c|c|c|c|}
\hline Sr no & Symptoms & Number of cases & Signs & Glossits \\
\hline 1 & Lethargy & 32 & Pallar & 10 \\
\hline 2 & Tingling and numbness & 18 & Angularcheilosis & 12 \\
\hline 3 & Abdominal pain & 12 & Sleenomegaly & 04 \\
\hline 4 & Fever & 08 & Hepatomegaly & 03 \\
\hline 5 & Weightloss, loss of appetite & 19 & Neural manifestation-Myopathy & 05 \\
\hline 6 & Alcoholism & 14 & Ecterus & 03 \\
\hline 7 & Pure vegetarian & 07 & & \\
\hline 8 & History of haemolyticanaemia & 06 & & \\
\hline
\end{tabular}

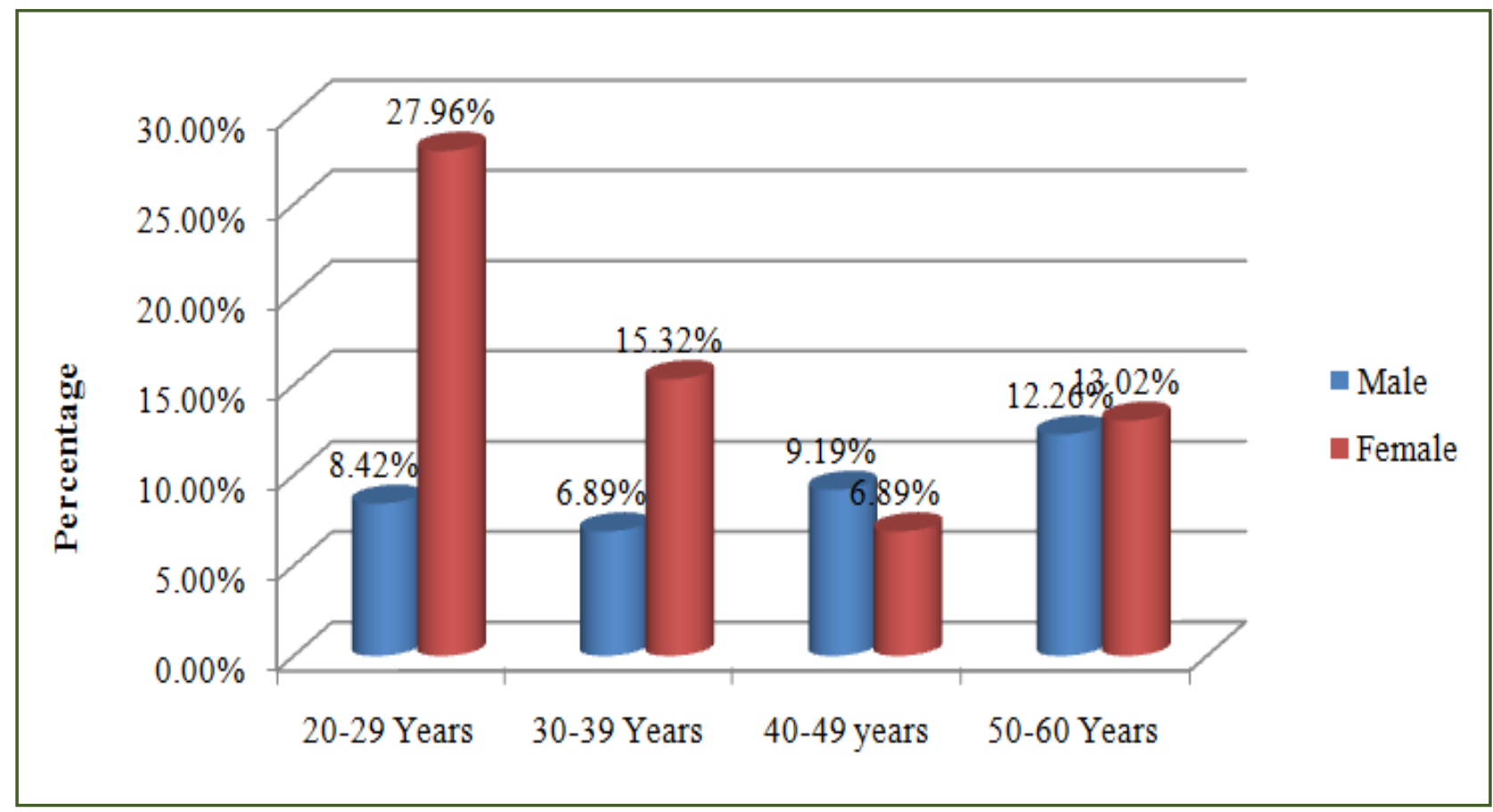

Graph 1: Distribution of cases of anemia in the study: Total= 261. 


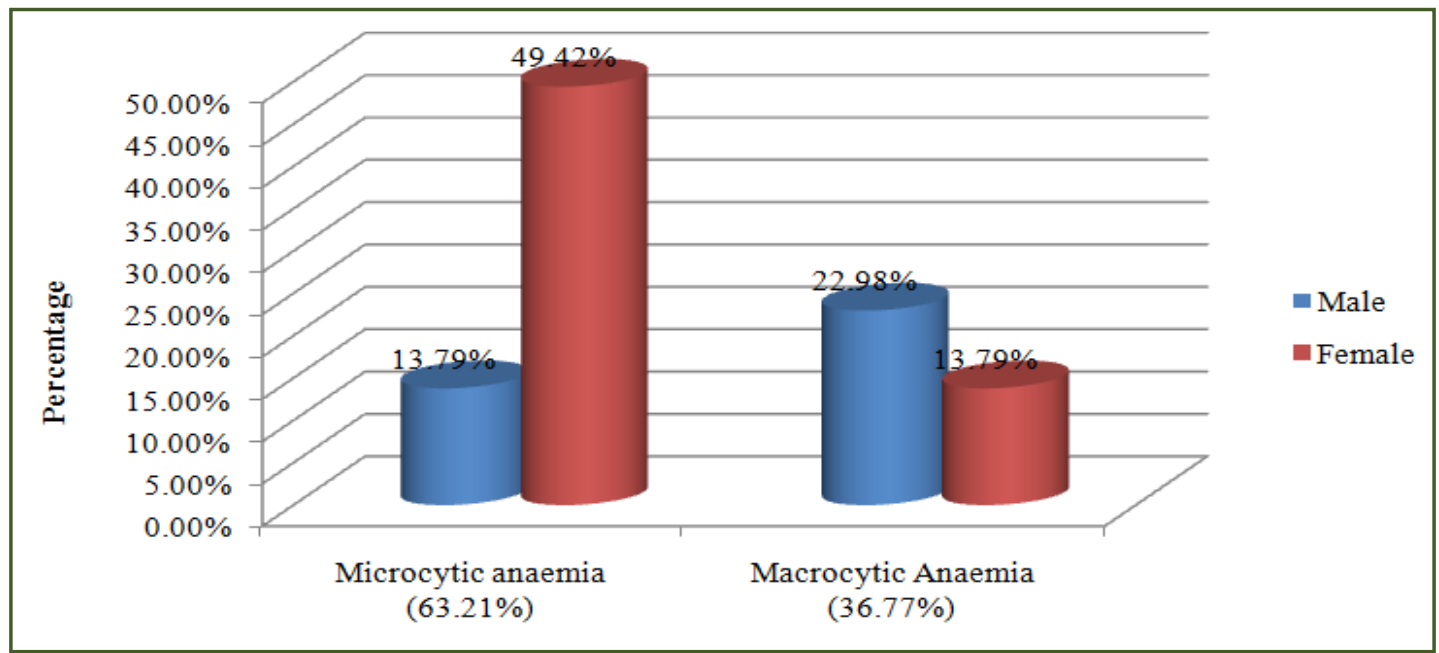

Graph 2: Distribution of cases according to type of anemia.

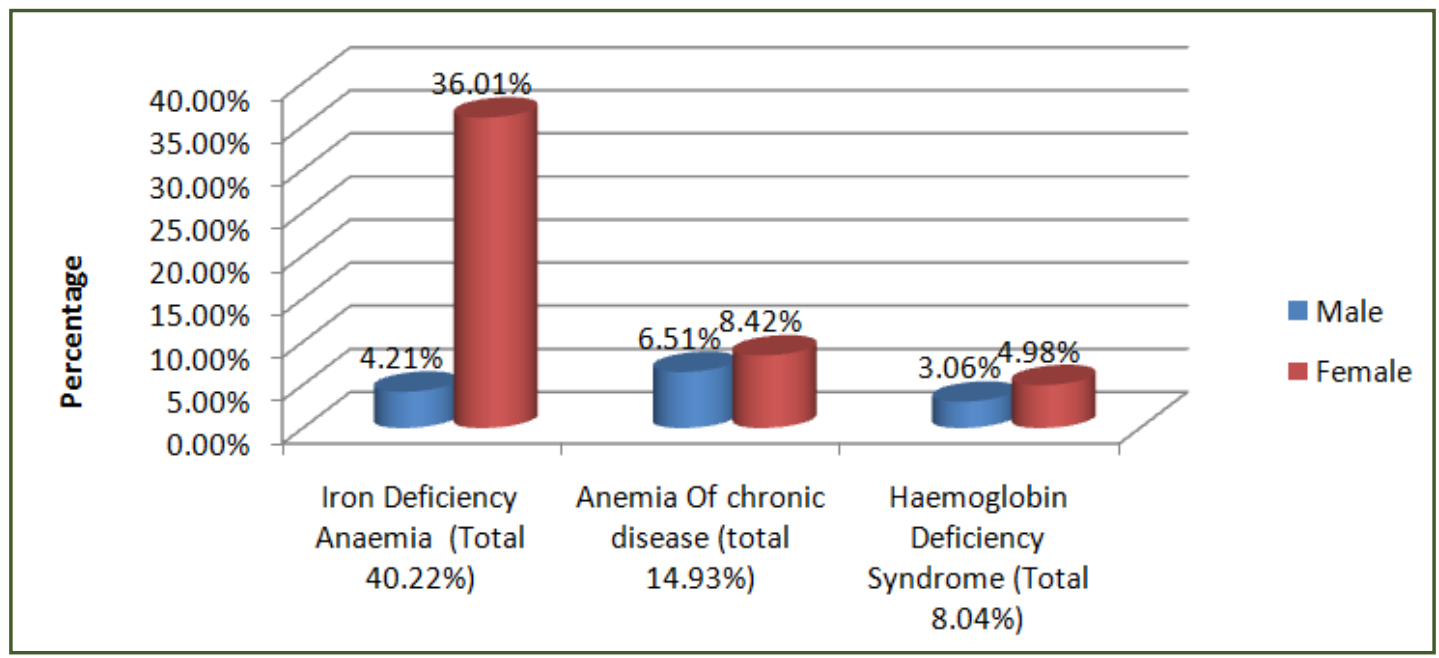

Graph 3: Distribution of cases of Microcytic hypochromic anaemia: Total; 165.

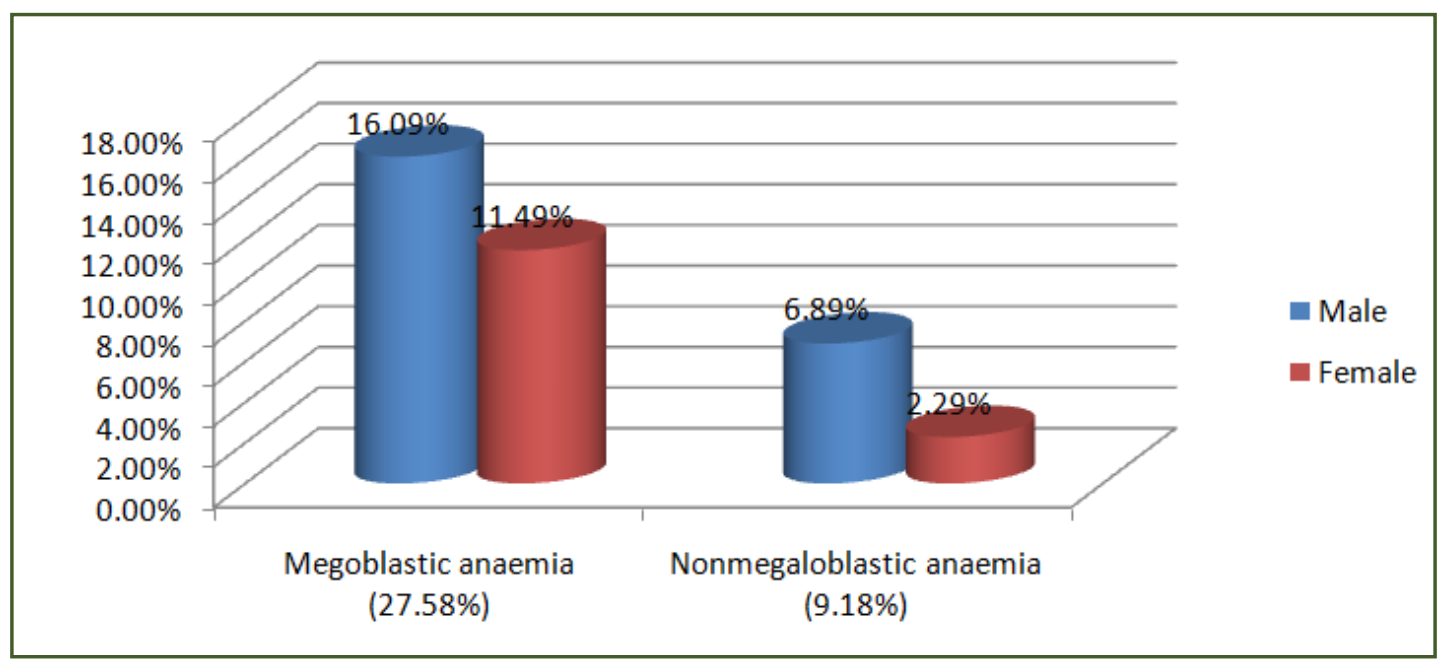

Graph4: Distribution of cases with Macrocytic anaemia:Total;96. 


\section{Discussion}

In women of childbearing age, the anemia prevalence is $30.2 \%$. Overall468.4 million women of childbearing age are anemic. The highest prevalence is found in Africa $(47.5 \%)$ and in South-East Asia (35.7\%). It is $17.8 \%$ in America, $14 \%$ in the United Arab Emirates; and from a low of $11 \%$ in Egypt to over $40 \%$ in the Syrian Arab Republic. Iron deficiency anemia was considered as important contribution of anemia in global burden of anemia in WHO report 2002. ${ }^{[7]}$

National Family Health survey in 2005-2006 showed, the prevalence of anemia was $55 \%$ in female aged $15-$ 49 years and $24 \%$ in male aged $15-49$ years. According to World Health Organization, there are two billion people with anemia in the world and half of anemia due to iron deficiency. ${ }^{[8]}$

In developing countries prevalence of nutritional anemia is $40 \%$, among the various nutritional anemia iron deficiency anemia is most commonIt is the most common nutritional disorder worldwide and accounts for approximately onehalf of anemia cases. ${ }^{[4,9]}$ In our study male was $36.78 \%$ and female was $63.21 \%$. Iron deficiency anemia was $40.22 \%$,more commonly seen in female with reproductive age group.

Patient with iron deficiency anaemia has history of decreased work or exercise tolerance, shortness of breath, palpitation. ${ }^{(6)}$ In the etiologies for iron deficiency anemia Terri D et al and Mathew W Short et al stated that itinclude blood loss like menorrhagia, epistaxis, melena, hematuria, and hematemesis.In developing countries decreased intake is primary cause of iron deficiencyanemia.. Other causes of anemia include chronic blood loss from gastrointestinal tract, gynecological disorder and genitourinary blood loss. Gastrointestinal bleeding can be acute or chronic. Patient present with maroon coloured stool or blood in stool. Bleeding may be associated with NSAID or aspirinIngynecological disorder postmenopausal women with excessive menstruation seen. ${ }^{[3,9]}$

In present study in microcytic hypochromic anemia patient present with symptoms like fatigue, palpitation, menstrual bleeding, few of them present with joint pain, Gastrointestinal bleeding, dyspnoea on exertion which is similler to finding of Terri $\mathrm{D}$ et $\mathrm{a}^{\left[{ }^{[3]}\right.}$ and Mathew $\mathrm{W}$ Short et a ${ }^{[9]}$

According to Mathew W Short et al diagnosis of iron deficiencyanemia requires laboratory confirmed evidence of anemia as well as evidence of low iron stores. Values consistent with iron deficiency include a low serum iron level, low transferrin saturation and high total iron binding capacity. Serum ferritin is particularly valuable in anemic patient because level below $12 \mathrm{ug} / \mathrm{L}$ is diagnostic of iron deficiency anemia ${ }^{[9,10,11]}$

In our study, $40.22 \%$ cases were with iron deficiency anaemia, $36.01 \%$ arefemale and $04.21 \%$ aremale, showed a decreased parameter below the normal range like serum iron, ferritin, transferrin saturation and increased TIBC above the normal level, similarfinding with Mathew W Short et al ${ }^{[9]}$

Other causes of microcytosis include chronic inflammatory state, lead poisoning and thalassemia and sideroblastic anemia. ${ }^{[9]}$ Hemoglobin level less than $9 \mathrm{gm} / \mathrm{dl}$ in patient with microcytic anemia and normal iron studies suggest $\mathrm{Hb} \mathrm{H}$ disease, B thalassemia major or intermedia. An increased RDW may be particularly helpful in distinguish between iron deficiency and thalassemia minor. A bone marrow aspirate for iron stain remains gold standard for iron deficiency anemia in difficult cases. ${ }^{\left[{ }^{12]}\right.}$ We performed Prussian blue stain for iron store in cases wherever it is possible in Iron deficiency anemia and showed decreased grading.

Ferritin is acute phage reactant protein, serum levels tend to be elevated in inflammatory condition. ${ }^{[12,13,14,15]}$ Ferritin is elevated in inflammation, autoimmune disorder, chronic infection and liver disease. Elevated levels of ferritin well established in still's disease, multiple sclerosis and rheumatoid arthritis. Ferritin also plays an important role in host immune response is evident from its increased concentration ${ }^{[13]}$ In anemia of chronic inflammation ferritin levels rises moderately achieving mean level such as 300$400 \mathrm{ug} / \mathrm{L}$ Ferritin criteria used for recognition of coexisting iron deficiency anemia in patient who have chronic inflammation.In the study of Sheetal Patel et al observed massive hyperferritinemia in adult onset stills desease. ${ }^{[14]}$

In our study $14.93 \%$ of cases showed increased ferritin above $100 \mathrm{ng} / \mathrm{ml}, 8.42 \%$ are female and $6.51 \%$ are male. Casesinclude various inflammatory conditions like respiratory disease, chronic urinary disease, rheumatoid arthritis and 2 cases of heart diseases

Megaloblastic anemia is more common in vegetarian than nonvegetarian. Folic acid deficiency more commonly seen in elder, children, pregnant women and haemolyticanaemia. Clinical feature of megaloblasticanaemia are anorexia, irritability, fatigue, palpitation. Commonest physical finding was pallor, fever, generalized weakness, splenomegaly, hepatomegaly and hypopigmentation. Common neurological manifestation of vit B12 deficiency includes parasthesia, weakness, gait abnormalities and behavior changes. ${ }^{[16,17,18]} \mathrm{In}$ the present study most of 
patient with macrocytic anemia presented with lethargy, tingling numbness, loss of appetite, loss of weight, pain in abdomen, fever and alcoholism

For laboratory diagnosis of megaloblastic anemia complete blood picture with PBS showed macrocytosis, hypersegmented neutrophil, raised MCV and RDW, assay of two vitamins (vit B12 and folic acid) and bone marrow aspiration required for definitive diagnosis. ${ }^{[16,17,18]}$

The severity of megaloblastic marocytosis is directly proportional to the severity of the anaemia and early megaloblastosis may manifest only mild change. Six lobed neutrophil may be absent and increased in four lobed and five lobed neutrophil may be evident or presence of one seven loabed neutrophil or two six lobed neutrophil or three five lobed neutrophil strongly suggest megaloblastic anemia. ${ }^{[12]}$ Anisocytosis and poikilocytosis is higher in megaloblastic anemia. ${ }^{[16,19]}$ We observed anisopoikilocytosis in most of cases in present study.

In our study $27 \%$ cases showed megaloblastic anemia On PBS showed macrocytes, macrovalocyte, occasional or one-two hypersegmented neutrophil or hypersegmented neutrophil not be seen in few cases, increased MCV, between 110-131fl, on haematology automated analyzer and presence of megaloblast in bone marrow aspiration.

The finding of MCV of more than $100 \mathrm{cu}$ microns quite helpful due to limited differential diagnosis. An MCV of more than $120 \mathrm{cu}$ microns almost always indicate megaloblastic anemia. If there is any doubt as to cause of macrocytic anemia, a bone marrow aspirate and biopsy should be done, in classic megaloblastic anemia one will see increased cellularity in the biopsy specimen. The aspirate will show erythroid hyperplasia, delayed nuclear maturation relative to haemoglobinization of the cytoplasm seen best in basophilic, polychrmatophilic and orthochromatophilic erythroblast. ${ }^{[12]}$ One author stated only minority of patient with MCV level above $100 \mathrm{fl}$ are deficient in vitB12 or folate. ${ }^{[, 20]}$

Moreover serum cobalamine levels may not be indicative of actual deficiency. Cobalamine levels may be falsely high in patient with megaloblastosis due to nitrous oxide,transcobalamine II deficiency.Vitamin B12 level may be significantly lower imMegaloblastic anemia $\left.{ }^{[21}\right]$

Only minority of patient with MCV level above $100 \mathrm{fl}$ are deficient with vitamin $\mathrm{B} 12$ or folate ${ }^{[20]}$ Patient with nonmegaloblastic macrocytic anemia haveMCV less than $120 \mathrm{cu}$ microns. Alcohol ingestion is commonest cause of mild macrocytosis. Other causes of macrocytosis are liver diseases, severe hypothyroidism and chemotherapy induced ${ }^{[12]}$

Annals of Applied Bio-Sciences, Vol. 4; Issue 2: 2017
In this study there are $9.18 \%$ cases with macrocytosis, in this case showed normal vit B12 and decreased or normal folic acid level

\section{Conclusion}

Result of this study demonstrates large number of iron deficiency anaemia cases seen in female with reproductive age group. In megaloblasticanaemia more number of cases are seen in age group between 50-60 years in both sex. For the diagnosis of microcytic hypochromic anemia haemogram by automated hematologyanalyzer, PBS examinationserum iron profile is necessary for correct diagnosis and for macrocytic anemia haemogram,PBS examination, bone Marrow aspiration cytology and assay of two vitamins like B12 and folic acid and reticulocyte are needed for diagnosis. Serum iron profile, vit B12, folic acid and bone marrow aspiration should be done in addition of PBS examination for correct diagnosis and treatment of nutritional anemia.

\section{Reference}

1. M.E.Bentley and P.L. Griffith. The burden of anemia among women in India. European Journal of Clinical Nutrition. 2003; 57:52-60.

2. Erin McLean, Mary Cogswell, Ines Egli, Daniel Wojdyla and Bruno de Benoist. Worldwide prevalence of anaemia. Public Health Nutrition. 2009 Apr;12(4):444-54.

3. Terri D. Johnson-Wimbley. Diagnosis and manegment of iron deficiency anemia in 21 st century. TherapAdv Gastrointestinol.2011; May 4 (3): 177-184.

4. Neelam S Deshpande, Devkinandan Karva, Sharad Angerkhedker, Shishir Deshpande. Prevalence of anemia in adolesant girl and its co-relation with demographic factors. International Journal of Medicine and Public Health. 2013;3(4):235-239.

5. Uma Khanduri, Archna Sharma. Megaloblasticanaemia: Prevalence and causative factors. The National Medical Journal of India.2007;20(4):172-175.

6. Robert $\mathrm{T}$ Means, Jr. BertiGlader. Anaemia Genaral Consideration. John Foester, George M Rodger and Frixos Paraskevas. Wintrobes Clinical Haematology. Volume I. Twelth Edition. Philedelphia; LIPPINCOTT WILLIUMS and WIKINS, a WOLKER KLUER bisiness. Page 779-807.

7. Fatin Al-Sayes, MamdoohGari, SafaaQusti ,NadiahBagatian and Adel Abuzenadah. Prevalence of iron deficiency and iron deficiency anemia among females at university stage. Journal of Medical Laboratory and Diagnosis. 2011; vol 2(1):5-11.

8. Gerardo Alvarez- Uria, Praveen K. Naik, Manoranjan Midde, Pradeep S Yalla and Raghavkalyan Pakam .Prevalace and severity of anaemia Stratified by Age Gender in Rural India. Anemia; 2014. dx.doi.org/10.115/2014/176182.

9. Matthew W. Short and Jason E. Domagalski. Iron Deficiency Anaemia. Evaluation and Management. Am Fam Physician 2013;87(2):98-104.

e-ISSN: 2349-6991; p-ISSN: 2455-0396 
10. Gangather T, Shrikanth $\mathrm{P}$ and Suneetha Y. Predictive value of iron store markers in anemia of chronic kidney disease. Journal of Chemical and Pharmaceutical Research. 2010;(3):400-410.

11. Berry S Skikne, Carol H Flowers and jams D cook. Serum Transferrin receptor:A Quantitative Measure of Tissue Iron Deficiency. Blood. 1990;7(9):1870-1876.

12. Ralph O. Wallerstein, Jr, MD,San Francisco. Laboratory evaluation of anemia, West J Med 1987;146:443-451.

13. Kamala Vanarsa, YujinYe,Jie Han ChunXie,Chandra Mohan and Tianfu Wu. Inflammation associated anemia and ferritin as disease marker in SLE. Arthritis Research and Therapy 2012;14:R182 doi:10.1186/ar4012

14. Sheetal Patel, SeyedMonemian, Avesha Khalid and Harvey Dosik. Iron Deficiency anaemia in Adult Onset Still's Disease With a Serum Ferritin of 26,387ug/L. Anemia .2011: 184748. Published online May 12, 2011.doi 10.115/2011/184748.

15. Matthis Lorenz, Josef Kletzmayr, Agnes nPerschl, Alexander furrer, Walter H Horl and Gere Sunder- Plassmann. Anaemia and Iron Dficienciesamoung Long Term Renal Transplant Recipiant.JournalOf the American Society of Nephrology 2002 vol 13 (3) Page 794-797.
16. Salama Haq, Nasir Eqbal, Fatima Fayyaz and Tahira Tasneem. Serum B12 and folate levels in patient with megaloblastic change in bone marrow. Biomedica. 2012; vol 28:35-41.

17. Robert C Langan and Kimberly J Zawistoski. Update on vit B12 Deficiency. Am Fam Physician 2011; 83(12):1425-1430.

18. M Ramani, D Ranganath, O.H. RadhikaKrishna, K geetha, M Kiteeka, Puja Deshmukh. Clinicopathological Review of Megaloblastic Anemia in Children-A 7 year paediatric Hospital Experience. Journal of evolution of Medical and Dental Sciences. 2013; 2(19):4136-4142.

19. Jeevan Sekhar and Sally P. Stabler. Life threating megaloblastic pancytopenia with normal mean cell volume: case series.. Eur J Inteern Med 2007; 18 (7): 548-550

20. John Lindenbaum. Status of laboratory testing in the diagnosis of Megaloblastic anemia. Blood 1983;64 (4): 624-627.

21. M Premkumar, $\mathrm{N}$ Gupta, $\mathrm{T}$ Singh and $\mathrm{T}$ Velpandian. Cobalamin and Folic Acid Status in Relation to the Etiopathgenesis of Pancytopenia in Adult at a tertiary Care centre in North India. Anemia.2012; http//dx.doi. org/10.11/2012/707402

*Corresponding author:

Dr Mangal Pandure, Dept of Pathology, Pravara Institue of Medical Sciences. Deemed University.

Email: mangal.garute11@gmail.com 